\title{
Tradução e retradução do romance Life of Pl: estudo exploratório de estilística tradutória com base em corpus paralelo bilíngue inglês/português
}

DOI: http://dx.doi.org/10.21165/el.v48i3.2309

\section{Raphael Marco Oliveira Carneiro'}

\section{Resumo}

Este artigo relata um estudo exploratório inicial e parcial de estilística tradutória baseado em corpus paralelo bilíngue inglês/português, de modo a comparar escolhas paradigmáticas e sintagmáticas de duas traduções de um mesmo texto-fonte no engendramento dos estilos dos textos traduzidos. Examinam-se a tradução e a retradução do primeiro capítulo do romance Life of Pi de Yann Martel em termos de quantidade de itens, formas e hapax legomena; razão forma/item; número de períodos; comprimento médio dos períodos; número de parágrafos; e escolhas lexicais e sintáticas. O estudo evidencia variações nos estilos da tradução e da retradução e sugere linhas para investigações futuras.

Palavras-chave: estilística tradutória; literatura canadense; português brasileiro.

1 Universidade Federal de Uberlândia (UFU), Uberlândia, Minas Gerais, Brasil; raphael.olic@gmail.com; https://orcid.org/0000-0001-7577-4631 


\title{
Translation and retranslation of the novel Life of Pi: a translational stylistic exploratory study based on English/Portuguese bilingual parallel corpus
}

\begin{abstract}
This paper reports on an initial and partial translational stylistic exploratory study based on English/Portuguese bilingual parallel corpus whose aim is to compare paradigmatic and syntagmatic choices of two translations of the same source text in engendering the styles of the translated texts. The translation and the retranslation of the first chapter of Yann Martel's novel Life of Pi are examined in terms of tokens, types and hapax legomena; type/token ratio; number of sentences; average sentence length, number of paragraphs; and lexical and syntactic choices. The study highlights variations in the style of the translation and of the retranslation and suggests further avenues of research.
\end{abstract}

Keywords: Brazilian Portuguese; Canadian Literature; translational stylistics.

\section{Introdução}

Em vista de recentes desenvolvimentos de abordagens estilísticas para análises descritivas de traduções literárias (BAKER, 2000; MALMKJAER, 2004; SALDANHA, 2011; NOVODVORSKI, 2013), este artigo busca contribuir com um estudo exploratório de estilística tradutória com base em um corpus literário paralelo bilíngue inglês/ português. Esta pesquisa, de modo geral, objetiva identificar traduções brasileiras de textos literários canadenses e conduzir análises estilísticas das traduções e retraduções de dois romances, The Handmaid's Tale (1985), de Margaret Atwood, e Life of Pi (2001), de Yann Martel. Para delimitar o escopo da presente análise, serão consideradas apenas a tradução e a retradução de Life of $P i$.

O estudo exploratório proposto constitui uma etapa dos procedimentos metodológicos da pesquisa que cumpre a função de apresentar ao pesquisador características parciais e preliminares do corpus de estudo, para que linhas de investigação sejam traçadas na condução de análises subsequentes. Trata-se de uma etapa que visa explicitar características do corpus que podem gerar questionamentos previamente não estabelecidos, de maneira que poderão vir a guiar etapas seguintes da metodologia, configurando, assim, um estudo direcionado por corpus.

Para conduzir este estudo, adotamos o pressuposto estruturalista elementar que rege a produção linguística humana de modo geral. A língua em uso é caracterizada por escolhas e pela organização dessas escolhas no discurso, de modo a constituir dois eixos de análise: o eixo paradigmático e o eixo sintagmático. Além disso, as escolhas de 
um enunciador na composição de um discurso configuram um estilo, ou seja, um modo de dizer particularizado pelas escolhas e propósitos de um enunciador e pelos contextos sociocultural e sociocognitivo de produção. No processo de tradução, o tradutor também realiza escolhas, mas em contextos diferentes que os da produção do texto original, o que pode ocasionar mudanças no estilo dos textos. Com base nessas considerações iniciais, este ensaio descritivo se configura como um estudo inicial e parcial de estilística tradutória com o objetivo de comparar escolhas paradigmáticas e sintagmáticas de duas traduções de um mesmo texto-fonte no engendramento dos estilos dos textos.

Tendo em vista uma apreciação de obras da Literatura Canadense traduzidas no Brasil e a título de contextualização, é importante ressaltar que as obras de Atwood contam com 23 traduções publicadas pela editora Rocco. Além disso, traduções de obras de Atwood têm sido publicadas desde 1980 por outras editoras, como Marco Zero, Editora Globo, Companhia das Letras e Morro Branco (CARNEIRO, 2018, 2019). Dentre as obras de Yann Martel, foram traduzidas no Brasil Life of Pi (uma tradução e uma retradução), Beatrice and Virgil, 101 Letters to a Prime Minister, e The High Mountains of Portugal (CARNEIRO, 2017).

Cabe ressaltar que esta investigação busca dar seguimento a uma tradição de pesquisas com foco em aspectos estilísticos de traduções e retraduções de textos literários, como as de Blauth (2014), Magalhães, Castro e Montenegro (2013). Tais pesquisas, que partem de metodologias com base em corpora informatizados, têm demonstrado a importância de se analisar os estilos de textos traduzidos em comparação aos estilos dos textos originais, no sentido de observar de forma mais minuciosa como as traduções variam em relação às retraduções quando comparadas ao mesmo texto-fonte. Assim, neste estágio de pesquisa buscamos descrever como a tradução e a retradução do romance Life of Pi diferem em escolhas paradigmáticas e sintagmáticas em relação ao texto-fonte.

Após essa breve introdução, seguiremos com a fundamentação teórica, os procedimentos metodológicos, a apresentação e análise dos dados, as considerações finais e as referências bibliográficas.

\section{Fundamentação teórica}

Para compor o referencial teórico-metodológico desta investigação, integramos Estudos Descritivos da Tradução (TOURY, 2012), Estudos da Tradução Baseados em Corpus (BAKER, 1993; LAVIOSA, 2002), Abordagens Estilísticas da Tradução (BAKER, 2000; MALMKJAER, 2004; SALDANHA, 2011), Teoria da Retradução (BERMAN, 1990; BROWNLIE, 2006; KOSKINEN; PALOPOSKI, 2003) e Estilística (GIBBONS; WHITELEY, 2018; JEFFRIES; MCINTYRE, 2010). A seguir, os conceitos e desenvolvimentos teóricos dos campos de investigação mencionados serão situados dentro do escopo do presente estudo. 


\section{Estudos da Tradução Baseados em Corpus}

Os Estudos Descritivos da Tradução constituem um ramo dos Estudos da Tradução que, juntamente com a Linguística de Corpus (BERBER SARDINHA, 2009), contribuíram para o alvorecer de um novo paradigma, os Estudos da Tradução Baseados em Corpus (LAVIOSA, 2002). Em Baker (1993), encontramos uma das primeiras tentativas de se considerar o uso de corpora nos Estudos da Tradução. A autora faz um percurso pelo estatuto dos Estudos da Tradução enquanto disciplina e aborda desenvolvimentos que justificam um movimento em direção à pesquisa com base em corpus. Baker (1993, p. 243, tradução nossa), então, afirma que "o efeito profundo que os corpora terão nos estudos da tradução [...] será consequência de seu potencial de nos permitir identificar características de textos traduzidos que nos ajudarão a entender o que é tradução e como ela funciona"2. Isto é, as contribuições trazidas pelo uso de corpora na pesquisa em tradução redimensionam o entendimento fundamental do que é e de como a tradução funciona. Baker (1993) ainda enfatiza que a metodologia e o conjunto de ferramentas necessárias para que se identifiquem características de textos traduzidos e que auxiliem no desenvolvimento do campo descritivo da disciplina estão disponíveis por meio da Linguística de Corpus.

Cabe explicitar que entendemos corpus como um construto teórico, que traz consigo uma concepção própria de língua, ou seja, um sistema probabilístico de escolhas resultantes de combinatórias lexicogramaticais (HALLIDAY, 1992). Além disso, concebemos a produção linguística como governada por dois princípios, o da livre escolha e o idiomático (SINCLAIR, 1991). Nessa perspectiva, entende-se que o falante goza de certa liberdade para escolher os elementos linguísticos que irão compor seus dizeres e, ao mesmo tempo, sofre restrições de natureza lexicogramatical e idiomática, ou seja, de unidades semi-pré-construídas disponíveis para atualização e que contribuem para a naturalidade das manifestações linguísticas.

Passaremos a tratar de algumas abordagens estilísticas da tradução.

\section{Abordagens Estilísticas da Tradução}

Pode-se dizer que o trabalho que inaugurou o estudo do estilo de traduções e de tradutores com base em corpus foi o de Baker (2000), em que ela busca traçar uma metodologia para a análise do estilo de tradutores literários. Desde então, surgiram várias contribuições para esse tipo de estudo, dentre as quais ressaltamos Malmkjaer (2004) e Saldanha (2011), no exterior, e Magalhães e Blauth (2015) e Novodvorski (2012), no Brasil. Tendo em vista

2 No original: "The profound effect that corpora will have on translation studies [...] will be a consequence of their enabling us to identify features of translated text which will help us understand what translation is and how it works". 
esses quase 20 anos de desenvolvimento, já é possível distinguir diferentes abordagens de análises estilísticas da tradução, as quais comentamos brevemente a seguir.

Baker (2000, p. 245, tradução nossa) propõe o estudo do estilo de tradutores em corpora comparáveis, entendendo estilo do tradutor como "[...] o modo de expressão típico de um tradutor [...] uso característico da língua por um tradutor [...] perfil individual de hábitos linguísticos, comparado aos de outros tradutores ${ }^{3 "}$. Essa noção traz consigo a de padrões linguísticos recorrentes que podem ser identificados por meio de técnicas computacionais advindas da Linguística de Corpus.

Malmkjaer (2004), por sua vez, trata de estilo como atributo textual, posição também adotada por Novodvorski (2013). Malmkjaer (2004, p. 14) define estilo como "[...] regularidade de ocorrências consistentes e estatisticamente significantes de certos itens e estruturas em textos, ou tipos de itens e estruturas, dentre aqueles oferecidos pela língua como um todo"4. Nessa perspectiva, chamada de estilística tradutória, entende-se que o estilo das traduções só pode ser descrito em comparação ao texto-fonte; "[...] a menos que essa relação seja considerada, muitas características textuais de interesse potencial não são percebidas pelo analista" (MALMKJAER, 2004, p. 16)5. Essa perspectiva se beneficia de corpora paralelos.

Saldanha (2011, p. 31, tradução nossa) propõe uma abordagem mista, que considera tanto o estilo da tradução quanto o estilo do tradutor, definido como:

'Modo de traduzir' que: é reconhecível em várias traduções de um mesmo tradutor; distingue o trabalho de um tradutor do trabalho de outros; constitui um padrão coerente de escolha; é 'motivado' no sentido de que tem uma função ou funções discerníveis; e não pode ser explicado puramente em referência ao autor ou estilo do texto-fonte, ou como resultado de restrições linguísticas ${ }^{6}$.

Para esta pesquisa, entendemos estilo como atributo textual, de modo que investigamos

3 No original: "[...] the manner of expression that is typical of a translator [...] the translator's characteristic use of language [...] individual profile of linguistic habits, compared to other translators".

4 No original: "[...] a consistent and statistically significant regularity of occurrence in text of certain items and structures, or types of items and structures, among those offered by the language as a whole".

5 No original: "[...] unless this relationship is taken into consideration, many textual features of potential interest are unlikely to come to the notice of the analyst".

6 No original: "A 'way of translating' which is felt to be recognizable across a range of translations by the same translator, distinguishes the translator's work from that of others, constitutes a coherent pattern of choice, is 'motivated', in the sense that it has a discernible function or functions, and 
de uma perspectiva descritiva os estilos das traduções e não das tradutoras, aproximandonos mais da perspectiva da estilística tradutória.

\section{Teoria da Retradução}

A prática de se retraduzir textos não é recente, haja vista as inúmeras retraduções da Bíblia, por exemplo, e não se restringe a textos literários, podendo incluir os mais variados gêneros discursivo-textuais. Contudo, a Hipótese da Retradução (HR) e os estudos dela decorrentes foram impulsionados somente a partir de 1990, com base nas ideias lançadas por Antoine Berman em relação a textos literários. Desde então, a hipótese tem germinado vários estudos que ou a confirmam ou a refutam e, ao refutar, propõem revisões à hipótese com base em evidências empíricas. Assim, os estudos em retradução dão mostras de que estão se consolidando, de modo que há autores, como Brownlie (2006), que já falam em uma 'Teoria da Retradução'.

Primeiramente, é preciso definir que "toda tradução feita após a primeira tradução de uma obra é, portanto, uma retradução" (BERMAN, 1990, p. 1)7. Considera-se que a retradução é uma segunda tradução na mesma língua da primeira tradução, e assim sucessivamente, haja vista quantas retraduções forem feitas de um mesmo texto-fonte. Assim como Koskinen e Paloposki (2003, p. 21), concordamos que "retraduções são objetos de estudo fascinantes", principalmente porque possibilitam que uma tradução ilumine a outra e, assim, oportunizam análises comparativas valiosas para aprimorarmos o entendimento de fenômenos tradutórios.

As autoras supracitadas levantam questionamentos em relação aos motivos de se produzir traduções de textos já traduzidos e em que aspectos as retraduções se diferem das primeiras traduções, apontando que "uma resposta possível, postulada pela chamada Hipótese da Retradução $(H R)$, é que retraduções marcam um retorno ao texto-fonte, após uma assimilação assumida realizada pelas primeiras traduções" (KOSKINEN; PALOPOSKI, 2003, p. 21) ${ }^{8}$. Em outras palavras, as primeiras traduções seriam domesticadoras, porque apagariam marcas da cultura estrangeira, enquanto as retraduções seriam estrangeirizadoras, porque salientariam os aspectos da cultura estrangeira. Tendo a primeira tradução apresentado a obra para a cultura-alvo, acredita-

cannot be explained purely with reference to the author or source-text style, or as the result of linguistic constraints".

7 No original: "Toute traduction après la première traduction d'une oeuvre est donc une retraduction".

8 No original: "Retranslations are a fascinating object of study. Why are new translations made out of texts which have already been translated, and how do these retranslations differ from first translations? One possible answer, posited by the so called Retranslation Hypothesis (RH), is that retranslations mark a return to the source text, after an alleged assimilation carried out by first translations". 
se que as retraduções gozam de maior liberdade para estrangeirizar, assemelhando-se, em decorrência disso, ao original. Porém, como se tem observado, esse nem sempre é o caso. Koskinen e Paloposki (2010) atestam a insuficiência das ideias de Berman (1990) e observam que não é da natureza das primeiras traduções serem domesticadoras e das segundas e subsequentes traduções serem estrangeirizadoras, ressaltando que há vários outros fatores que contribuem para a determinação dos perfis textuais de traduções. As autoras, então, mencionam que as unidades que têm sido utilizadas para comparar as (re)traduções e determinar a proximidade com o original são, dentre outras, sintaxe, escolhas lexicais, itens culturais específicos, formas de tratamento, unidades de medida, língua falada, dialetos e gírias.

Massadier-Kenney (2015) observa que a HR foi fundada em um discurso da falta, o qual constitui a tradição crítica dominante. De fato, quando se observam as razões para retraduções elencadas por Gambier (1994), vemos que as retraduções estão calcadas em faltas nas traduções iniciais, de modo que as retraduções são feitas para suprirem as faltas das traduções e, assim, aprimorá-las, seja por meio de correções de erros, acréscimo de passagens censuradas ou omitidas, linguagem datada, novas interpretações ao texto, esclarecimento de alusões, aprimoramento do estilo "atrapalhado" da primeira tradução, etc. Massadier-Kenney (2015) reconhece que há estudos de caso que já questionam a noção de inadequação das primeiras traduções, mas que, mesmo assim, o discurso da falta prevalece, gerando uma corrente de pensamento que trata das traduções e das retraduções como polos opositivos, sendo as primeiras traduções o polo negativo, defeituosas, e as retraduções o polo positivo, aprimoradas. Por isso, a autora mencionada propõe um redirecionamento do pensamento sobre retradução, de tal forma que as retraduções sejam vistas não como originárias de inadequações ou deficiências em traduções anteriores, mas como originárias do poder da tradução de constituir um texto como literatura, do potencial literário de um texto, instaurando, assim, um discurso não da falta, mas da mobilidade, multiplicidade e pluralidade.

Para concluir, a noção de estilo se articula à de retradução, uma vez que diferentes traduções, de diferentes tradutores, de um mesmo texto-fonte tendem a apresentar estilos diferentes e, se a HR se aplica, o estilo da retradução seria mais semelhante ao estilo do texto-fonte do que ao da tradução.

Feita essa breve explanação sobre retradução, trataremos da importância de ideias estruturalistas para uma investigação inicial de estilo em textos.

\section{Estilística e Estruturalismo}

A Estilística é uma disciplina que se dedica ao estudo integrado da língua e da literatura (GIBBONS; WHITELEY, 2018); constitui-se como um campo eclético (JEFFRIES; MCINTYRE, 2010) que prima pela interdisciplinaridade e integração de perspectivas 
teórico-metodológicas diversas que melhor auxiliem em abordagens linguísticas tanto de textos literários quanto de textos não-literários. O texto, portanto, é o objeto central da Estilística que busca explicitar significados por meio de análise textual.

Os estudos estilísticos tiveram a contribuição de desenvolvimentos da linguística como um todo; uma dessas contribuições vem do estruturalismo no tocante aos dois eixos de organização linguística. Apesar das críticas sofridas, seus conceitos básicos têm muito a oferecer ao estilólogo. Pillière (2018) aponta que, ao adotar a perspectiva estruturalista como ponto de partida, de que a língua é um sistema e de que a interação entre os eixos paradigmático e sintagmático produz significados, torna-se possível oferecer uma descrição de aspectos estilísticos. Assim, entendemos que, "enquanto uma abordagem estruturalista não fornece todas as chaves, ela ainda pode certamente abrir algumas portas" (PILLIĖRE, 2018, p. 33, tradução nossa9).

De acordo com Jakobson (2003, p. 30), "a linguagem implica dois eixos. A sintaxe se ocupa do eixo dos encadeamentos (concatenação), a semântica do eixo das substituições". De modo mais explícito, a sintaxe, situada no eixo horizontal, sintagmático, ocupa-se das relações de combinação de unidades linguísticas menores em unidades linguísticas maiores, enquanto a semântica, situada no eixo vertical, paradigmático, ocupa-se das relações de substituição de uma unidade linguística por outra unidade que the é alternativa, com a qual compartilha semelhanças e diferenças. Em outras palavras, "a seleção (e, correlativamente, a substituição) concerne às entidades associadas no código, mas não na mensagem dada, ao passo que, no caso de combinação, as entidades estão associadas em ambos ou somente na mensagem efetiva" (JAKOBSON, 2003, p. 40).

Por meio de métodos da Linguística de Corpus as relações de combinação e seleção podem ser facilmente observadas de modo empírico, o que será exemplificado no contexto deste trabalho quando da apresentação e discussão dos dados.

Na seção seguinte, serão explicitados os procedimentos metodológicos adotados.

\section{Procedimentos metodológicos}

Para a realização do presente estudo, procedimentos básicos da pesquisa com corpus foram utilizados. Esses procedimentos podem ser sintetizados em planejamento, compilação, armazenamento e pré-processamento do corpus (limpeza, etiquetagem, etc.); processamento do corpus por meio de ferramenta computacional; extração de dados quantitativos (resultados da quantificação dos dados de forma numérica); extração de dados linguísticos (amostras/evidências do uso linguístico atestado no corpus); e, por

9 No original: "While a structuralist approach does not hold all the keys, it can still certainly open a few doors". 
fim, análise qualitativa dos dados numéricos e linguísticos.

Para o desenvolvimento deste estudo exploratório, apenas o primeiro capítulo do romance Life of Pi (2001), de Yann Martel e seus correspondentes na tradução A Vida de Pi (2004), de Alda Porto e na retradução A Vida de Pi (2010), de Maria Helena Rouanet, foram considerados. Optamos por analisar uma amostra dos textos para traçar linhas de investigação que poderiam não ser consideradas previamente. Desse modo, ao final da análise espera-se que tenhamos condições de propor caminhos a serem levados a cabo quando da conclusão da pesquisa.

A amostra selecionada dos textos em questão apresenta as seguintes características:

Quadro 1. Tipologia do corpus de estudo

\begin{tabular}{|l|l|}
\hline Língua & Bilíngue (inglês/português) \\
\hline Modo & Escrito (narrativas) \\
\hline Data de publicação & Sincrônico (2001-2010) \\
& Contemporâneo \\
\hline Seleção & Amostragem (linguagem de textos ficcionais) \\
& Estático (seleção não renovável) \\
\hline Conteúdo & Especializado (textos literários ficcionais) \\
\hline Autoria & Língua nativa (inglês), língua nativa (português) \\
\hline Disposição interna & Paralelo (original e traduções) \\
\hline Tamanho & 4992 itens (original e traduções) \\
\hline Nível de codificação & Uso de cabeçalho; etiquetagem de períodos e itálico \\
\hline Uso na pesquisa & Estudo (análise estilística) \\
\hline
\end{tabular}

Fonte: Elaboração própria

O Quadro 2, apresentado em sequência, ressalta informações pertinentes às obras que compõem o corpus: 
Quadro 2. Informações das obras do corpus de estudo

\begin{tabular}{|c|c|c|c|c|}
\hline Título & Autor/Tradutoras & Editora & $\begin{array}{c}\text { Ano de } \\
\text { publicação }\end{array}$ & $\begin{array}{c}\text { Edição } \\
\text { usada no } \\
\text { corpus }\end{array}$ \\
\hline Life of Pi (LoP_YM) & Yann Martel & Canongate & 2001 & 2003 \\
\hline A Vida de Pi (AVdP_AP) & Alda Porto & Rocco & 2004 & 2004 \\
\hline $\begin{array}{c}\text { A Vida de Pi (AVdP_ } \\
\text { MHR) }\end{array}$ & Maria Helena Rouanet & Nova Fronteira & 2010 & 2010 \\
\hline
\end{tabular}

Fonte: Elaboração própria

Destacamos que o pré-processamento do corpus inclui a etiquetagem de períodos para a contagem pelo programa de análise. Essa etiquetagem foi realizada por meio dos comandos "localizar" e "substituir" do programa Microsoft Word. Foram localizados os sinais de pontuação "., ?, !", os quais foram substituídos pela etiqueta indicativa de final de período $\langle/ s>$; na verdade, os sinais de pontuação são preservados com a adição das etiquetas. A etiquetagem foi revisada em seguida para eliminar casos em que o ponto final não indica final de período, como na abreviação de itens lexicais.

O programa utilizado para o processamento do corpus é o programa WordSmith Tools 6.0 (SCOTT, 2012) e duas de suas ferramentas: Concord e WordList que podem ser assim caracterizadas:

WordList: produz listas de palavra contendo todas as palavras do arquivo ou arquivos selecionados, elencadas em conjunto com suas freqüências absolutas e percentuais. Também compara listas, criando listas de consistência, onde é informado em quantas listas cada palavra aparece.

Concord: realiza concordâncias, ou listagens de uma palavra específica (o 'nódulo', node word ou search word) juntamente com parte do texto onde ocorreu. Oferece também listas de colocados, isto é, palavras que ocorrem perto do nódulo. (BERBER SARDINHA, 2009, p. 9).

Os dados obtidos pelo processamento do WST incidem na análise da seleção e combinação de unidades lexicais. Por meio da lista de palavras são obtidas as unidades lexicais mais frequentes que, em seguida, são observadas em seus contextos linguísticos de ocorrência. Dito de outra forma, as listas de palavras oferecem uma visão paradigmática e as linhas de concordâncias, apesar de favorecem a leitura vertical (paradigmática) das ocorrências, oportunizam a leitura sintagmática de coocorrências. 
Além disso, para a análise paradigmática são utilizados o COMPARA e o Corpus do Português, ambos com interfaces de consulta disponíveis na $W_{e} b^{10}$. O COMPARA, por ser um corpus com traduções em português, oportuniza a investigação de escolhas tradutórias alternativas às encontradas no corpus de estudo. Saldanha (2011, p. 29, tradução nossa) afirma que "[...] um corpus de controle (COMPARA) é usado para estabelecer qual das escolhas dos dois tradutores é mais proeminente em relação a um corpo maior de textos traduzidos"11. O Corpus do Português permite verificar ocorrências de unidades lexicais do corpus de estudo em usos gerais da língua portuguesa e sua distribuição em gêneros e variedades de diferentes nações falantes de português.

Na próxima seção, apresentamos e discutimos os dados obtidos.

\section{Apresentação e análise dos dados}

Nesta seção são apresentados os dados obtidos por meio das ferramentas Concord e WordList do programa de análise lexical WordSmith Tools 6.0. Principiamos com os dados estatísticos (Tabela 1) fornecidos pela lista de palavras.

Tabela 1. Dados estatísticos do corpus

\begin{tabular}{|c|c|c|c|}
\hline & 1. LoP_YM & AVdP_AP & AVdP_MHR \\
\hline Itens & 1.627 & 1.575 & 1.790 \\
\hline Formas & 722 & 779 & 837 \\
\hline $\begin{array}{l}\text { Razão forma/item } \\
\text { padronizada }\end{array}$ & 47,60 & 50,90 & 52 \\
\hline Número de períodos & 99 & 98 & 98 \\
\hline $\begin{array}{l}\text { Comprimento médio } \\
\text { dos períodos }\end{array}$ & 16,15 & 15,78 & 17,78 \\
\hline Número de parágrafos & 18 & 20 & 18 \\
\hline
\end{tabular}

Fonte: Elaboração própria

10 O COMPARA e o Corpus do Português podem ser respectivamente acessados nos seguintes endereços eletrônicos: https://www.linguateca.pt/COMPARA/, http://www.corpusdoportugues. org/

11 No original: "[... a control corpus (COMPARA) is used to establish which of the two translators' choices is more prominent in relation to a larger body of translated work". 
As seis medidas numéricas da Tabela 1, quando comparadas entre cada um dos três textos do corpus, apontam para algumas características estilísticas dos textos sob análise. A primeira delas indica a quantidade total de palavras (itens) do primeiro capítulo do texto-fonte, da tradução e da retradução. Observa-se que houve um aumento de 215 itens de uma tradução para a outra, assim como em relação ao número de formas; a retradução apresenta 58 formas a mais do que a tradução. Como consequência desses acréscimos, a razão padronizada entre as formas e os itens sugere que a retradução é lexicalmente mais diversa do que a tradução. Os dados também sugerem que a retradução tem em média duas palavras a mais na composição dos períodos do que a tradução. Mesmo assim, o número de períodos se manteve entre tradução e retradução (98 períodos), enquanto o original apresenta um período a mais do que as traduções. Enquanto a retradução preserva o mesmo número de parágrafos do texto-fonte (18), a tradução apresenta dois parágrafos a mais.

Numericamente, a tradução apresenta valores mais próximos do texto-fonte do que a retradução em relação ao número de itens, formas, razão forma/item padronizada e comprimento médio dos períodos. Mesmo sendo problemático esse tipo de comparação de dados de textos provenientes de sistemas linguísticos diferentes, é possível afirmar que a tradução apresenta um estilo mais sintético, ao fazer uso de menos palavras e períodos mais curtos do que a retradução. Em outras palavras, na retradução há mais palavras e períodos mais longos para um mesmo capítulo que foi inicialmente traduzido com uso de menos unidades lexicais. Haveria alguma motivação subjacente para esse aumento no número de itens e formas e tamanho dos períodos? Teria a retradução usado mais palavras para deixar significados mais claros e explícitos? Qual seria o impacto dessas divergências na leitura da tradução e da retradução? Essas são algumas das perguntas que surgem diante dos dados obtidos, as quais serão futuramente investigadas.

Dentre os dados numéricos fornecidos pela lista de palavras, é importante levar em conta o número total de formas em relação às formas com duas ocorrências ou mais e as formas que ocorrem apenas uma vez (hapax legomena).

Tabela 2. Número de formas e de hapax legomena

\begin{tabular}{l|l|l}
\hline & formas: total/ freq. $\geq \mathbf{2}$ & hapax legomena \\
\hline LoP_YM & $722 / 187$ freq. $\geq 2$ & 535 \\
\hline AVdP_AP & $779 / 167$ freq. $\geq 2$ & 612 \\
\hline AVdP_MHR & $837 / 203$ freq. $\geq 2$ & 634 \\
\hline
\end{tabular}

Fonte: Elaboração própria 
Os dados da Tabela 2 indicam que a retradução apresenta um número maior de formas mais frequentes $(\geq 2)$, ou seja, há 36 formas mais frequentes na retradução do que na tradução. Ao mesmo tempo em que há mais formas na retradução elas também são usadas com mais frequência. Há também número maior de hapax legomena, 22 a mais na retradução do que na tradução. Esses dados sugerem que o conjunto lexical da retradução é mais variado do que o da tradução, o que corrobora a razão forma/item padronizada. Considerando a amplitude de unidades lexicais usadas nas traduções como uma característica estilística dos textos, esse indício aponta para uma diferença de estilo entre as traduções.

Em sequência, na Figura 1, apresentamos as trinta primeiras palavras mais frequentes no corpus de estudo em comparação à tradução (no centro) e à retradução (à direita).

\begin{tabular}{|c|c|c|c|c|c|c|c|c|c|c|c|}
\hline $\mathrm{N}$ & Word & Freq. & $\%$ & $\mathrm{~N}$ & Word & Freq. & $\%$ & $\mathrm{~N}$ & Word & Freq. & $\%$ \\
\hline 1 & THE & 85 & 5,22 & 1 & DE & 87 & 5,52 & 1 & $\mathrm{DE}$ & 91 & 5,08 \\
\hline 2 & OF & 61 & 3,75 & 2 & A & 61 & 3,87 & 2 & A & 62 & 3,46 \\
\hline 3 & I & 56 & 3,44 & 3 & $E$ & 44 & 2,79 & 3 & QUE & 58 & 3,24 \\
\hline 4 & A & 47 & 2,89 & 4 & QUE & 34 & 2,16 & 4 & $E$ & 44 & 2,46 \\
\hline 5 & AND & 44 & 2,70 & 5 & O & 32 & 2,03 & 5 & O & 39 & 2,18 \\
\hline 6 & MY & 34 & 2,09 & 6 & NÃO & 23 & 1,46 & 6 & UM & 35 & 1,96 \\
\hline 7 & IN & 32 & 1,97 & 7 & SE & 23 & 1,46 & 7 & NÃO & 26 & 1,45 \\
\hline 8 & TO & 23 & 1,41 & 8 & DA & 22 & 1,40 & 8 & UMA & 21 & 1,17 \\
\hline 9 & IS & 21 & 1,29 & 9 & EM & 20 & 1,27 & 9 & COM & 18 & 1,01 \\
\hline 10 & IT & 18 & 1,11 & 10 & $\mathrm{ME}$ & 20 & 1,27 & 10 & OS & 18 & 1,01 \\
\hline 11 & $\mathrm{ME}$ & 17 & 1,04 & 11 & UM & 19 & 1,21 & 11 & SE & 18 & 1,01 \\
\hline 12 & ON & 17 & 1,04 & 12 & É & 18 & 1,14 & 12 & DA & 17 & 0,95 \\
\hline 13 & AT & 16 & 0,98 & 13 & UMA & 18 & 1,14 & 13 & É & 17 & 0,95 \\
\hline 14 & THAT & 16 & 0,98 & 14 & DO & 16 & 1,02 & 14 & EM & 17 & 0,95 \\
\hline 15 & WITH & 15 & 0,92 & 15 & EU & 13 & 0,83 & 15 & PARA & 16 & 0,89 \\
\hline 16 & THREE & 12 & 0,74 & 16 & os & 13 & 0,83 & 16 & POR & 16 & 0,89 \\
\hline 17 & SLOTH & 11 & 0,68 & 17 & DEDOS & 12 & 0,76 & 17 & AS & 14 & 0,78 \\
\hline 18 & THEY & 11 & 0,68 & 18 & NO & 12 & 0,76 & 18 & $\mathrm{ME}$ & 13 & 0,73 \\
\hline 19 & ARE & 10 & 0,61 & 19 & PREGUIÇA & 12 & 0,76 & 19 & DO & 12 & 0,67 \\
\hline 20 & BUT & 10 & 0,61 & 20 & TRES & 12 & 0,76 & 20 & MINHA & 11 & 0,61 \\
\hline 21 & ITS & 10 & 0,61 & 21 & $\mathrm{COM}$ & 11 & 0,70 & 21 & NA & 11 & 0,61 \\
\hline 22 & LIFE & 10 & 0,61 & 22 & VIDA & 11 & 0,70 & 22 & NO & 11 & 0,61 \\
\hline 23 & TOED & 10 & 0,61 & 23 & PARA & 10 & 0,63 & 23 & OU & 11 & 0,61 \\
\hline 24 & WAS & 10 & 0,61 & 24 & COMO & 9 & 0,57 & 24 & ELA & 10 & 0,56 \\
\hline 25 & LIKE & 9 & 0,55 & 25 & MINHA & 9 & 0,57 & 25 & VIDA & 10 & 0,56 \\
\hline 26 & NOT & 9 & 0,55 & 26 & OU & 9 & 0,57 & 26 & COMO & 9 & 0,50 \\
\hline 27 & OR & 9 & 0,55 & 27 & POR & 9 & 0,57 & 27 & TRÊS & 9 & 0,50 \\
\hline 28 & HAVE & 8 & 0,49 & 28 & NA & 8 & 0,51 & 28 & DEDOS & 8 & 0,45 \\
\hline 29 & SLOTHS & 8 & 0,49 & 29 & AS & 7 & 0,44 & 29 & EU & 8 & 0,45 \\
\hline 30 & so & 8 & 0,49 & 30 & MAS & 7 & 0,44 & 30 & PREGUIÇA & 8 & 0,45 \\
\hline
\end{tabular}

Figura 1. Trinta primeiras palavras mais frequentes do corpus de estudo (da esquerda para a direita temos LoP_YM, AVdP_AP, AVdP MHR)

Fonte: Elaboração própria 
Nota-se a alta ocorrência de palavras gramaticais tanto no texto-fonte como nos dois textos-alvo. Ressaltamos as ocorrências dos pronomes I, my, e me, elementos dêiticos que identificam as pessoas do discurso, nesse caso, o narrador-personagem Piscine Molitor Patel, conhecido como Pi. Em termos de palavras lexicais, além dos verbos are, was e have, identificamos life, three, sloth(s), toed. Essas três últimas unidades, na verdade, fazem parte de um item lexical maior three-toed sloth(s). Também há ocorrências na lista (que não aparecem no recorte da Figura 1) de palavras como religious, studies, zoology, academic com frequências igual ou maior do que dois. Assim, os itens lexicais mais frequentes (freq. $\geq 2$ ) revelam que o primeiro capítulo estabelece a relação central da trama traçada entre a personagem principal Pi (I: 56, MY: 34, ME: 17), animais (SLOTH: 11), vida (LIFE: 10), religião (RELIGIOUS: 6) e ciência (STUDIES: 4; ZOOLOGY: 3; ACADEMIC: 2), o que também se confirma tanto na tradução quanto na retradução.

A frequência maior da forma QUE (58) na retradução pode ser um indício de maior explicitação do que na tradução, a qual apresenta 24 ocorrências a menos do pronome QUE. Contudo, está além do escopo deste estudo uma investigação mais detalhada dessa questão.

Um item lexical que nos chamou a atenção foi o hapax legomenon sorumbático usado na tradução. Ao gerar uma linha de concordância para esse nódulo, notamos o seu uso na primeira frase do texto.

(01) Meu sofrimento deixou-me triste e sorumbático. (AVdP_AP)

(02)므 sofrimento me deixou triste e melancólico. (AVdP_MHR)

Os exemplos acima são as duas traduções dadas para o período My suffering left me sad and glommy (LoP_YM). Ao olhar para o eixo paradigmático, ou seja, o eixo da seleção de opções tradutórias, é notável a diferença de opções entre a tradução e a retradução, principalmente quando levadas em conta outras opções tradutórias encontradas no COMPARA. Das 22 opções de tradução para gloomy na direção inglês>português, 8 foram sombria(o)(os), 3 lúgubre, 2 melancólico(as), 2 triste, depressivo, taciturno, escuro, soturna, negros, escuras (cada uma com uma ocorrência), e um caso em que não foi possível localizar um equivalente para o nódulo pesquisado. Percebe-se então que, na tradução, fez-se uma escolha pouco frequente dentre as opções que comumente são usadas em outras traduções literárias. Na retradução, por sua vez, optou-se por um item lexical, melancólico, que encontra respaldo em um corpus maior de textos traduzidos.

Investigando mais profundamente, descobrimos que, de acordo com o Corpus do Português, a forma sorumbático é mais frequente no português europeu do que no português brasileiro, enquanto a forma melancólico é mais frequente no português brasileiro. Também descobrimos que sorumbático é uma unidade lexical de maior 
ocorrência no universo de discurso ficcional do que em outros universos, como o acadêmico, o jornalístico e o oral. Melancólico, por sua vez, é uma unidade lexical de maior ocorrência na ficção, mas também apresenta usos nos universos de discurso acadêmico e jornalístico.

No eixo sintagmático, ou seja, de combinação de unidades lexicais, observamos as coocorrências no Corpus do Português para os nódulos sorumbático e melancólico. Há 12 ocorrências de triste no cotexto de melancólico contra 2 ocorrências de triste no cotexto de sorumbático. Dessas 12 ocorrências, 4 são de triste e melancólico, 3 são de melancólico e triste, 4 de triste, melancólico, e 1 de melancólico e estás triste. Nota-se uma tendência na coocorrência entre triste e melancólico como uma espécie de binômio (unidade fraseológica em que duas palavras de mesma classe gramatical coocorrem unidas por uma conjunção). Das 2 ocorrências de sorumbático com triste, uma foi triste e sorumbático, e a outra triste, sorumbático. Em ambos os casos, há precedência na língua portuguesa do uso combinado triste e sorumbático, e triste e melancólico, sendo a combinação triste e melancólico mais frequente. Essas observações nos levam a hipotetizar que talvez haja uma tendência de que na retradução tenham sido feitas escolhas tradutórias de uso mais frequente ou usual no português brasileiro. Para verificar essa hipótese, será necessário observar se há um padrão nessas escolhas ao longo do romance como um todo. A escolha de sorumbático, por não ser uma opção tradutória imediata para gloomy, nos leva a considerá-la um caso de escolha marcada do ponto de vista estilístico.

Nos exemplos (01) e (02) também chamam a atenção as diferentes opções de colocação pronominal. Nesses casos, o uso da ênclise e da próclise é opcional, de modo que a escolha de um caso pelo outro em traduções diferentes aponta para traços estilísticos de natureza sintática que distinguem as duas traduções. Enquanto a tradução optou pela ênclise, a retradução optou pela próclise. Ao computar as linhas de concordância para o pronome me, obtivemos os dados apresentados no Quadro 3.

Quadro 3. Colocação pronominal entre tradução e retradução

\begin{tabular}{|l|l|}
\hline AVdP_AP & AVdP_MHR \\
\hline deixou-me triste & me deixou triste \\
\hline lembrar-me da loucura & me lembrar que a ambição \\
\hline o garçom olhou-me, crítico & o garçom me olhou com um ar de crítica \\
\hline trouxeram-me [...] de volta à vida & me trazendo de volta à vida \\
\hline consegui erguer-me & conseguia ficar de pé \\
\hline provocavam-me [...] acessos de riso & $\begin{array}{l}\text { acabavam me fazendo ter acessos de } \\
\text { risos }\end{array}$ \\
\hline provocou-me tamanho choque & fiquei atordoado \\
\hline
\end{tabular}

Fonte: Elaboração própria 
Esses exemplos indicam que há um padrão de escolhas. Para os casos em que na tradução há uso de ênclise, na retradução há uso de próclise ou de locução. A ênclise é geralmente associada a registros mais formais e escritos de uso da língua, enquanto a próclise tende a ser mais associada a registros informais e orais de uso. Nesse sentido, podemos hipotetizar que a retradução tem uma tendência a preferir escolhas mais próximas da oralidade do que a tradução. Teriam essas escolhas respaldo no romance como um todo?

A diferença de escolhas para a tradução do pronome my no sintagma nominal my suffering como meu sofrimento na tradução e o sofrimento na retradução também sugere uma questão estilística interessante com desdobramentos para a representação mental construída na leitura do texto. A escolha por meu sofrimento em (01) mantém a ideia de sofrimento pessoal, subjetivo, interno, enquanto a escolha por o sofrimento em (02) atribui uma dimensão objetiva ao sofrimento, representado como algo impessoal, exterior à pessoa que fala. A escolha diferente de elementos dêiticos posiciona o leitor ora mais imerso no mundo ficcional (meu sofrimento), ora mais distante dele (o sofrimento). Desse modo, a tradução e a retradução apontam para a construção de representações ou posicionamentos dêiticos distintos que podem ter desdobramentos na experiência de leitura.

Dado o escopo do artigo, restringimo-nos à apresentação dos dados anteriores que, apesar de limitados, apontam para algumas direções, as quais serão indicadas na seção seguinte.

\section{Considerações finais}

Examinaram-se neste estudo exploratório a tradução e a retradução do primeiro capítulo do romance canadense Life of Pi de Yann Martel. As traduções brasileiras de Alda Porto e Maria Helena Rouanet foram comparadas em termos de quantidade de itens, formas e hapax legomena; razão forma/item; número de períodos; comprimento médio dos períodos; número de parágrafos; e escolhas lexicais e sintáticas. Fez-se uso de corpora de referência da língua portuguesa para efeitos de comparação de escolhas tradutórias; um dos corpora com textos traduzidos em português e outro de textos "originalmente" escritos em português. No estágio atual da pesquisa ainda não temos condições de fazer uma apreciação dos dados encontrados face à Hipótese da Retradução. O que os dados apenas sugerem é que a retradução, na análise da amostra de um caso específico, aparenta se aproximar mais de um registro informal do português brasileiro, o que levaria a supor que esta seria mais próxima da língua-alvo do que a tradução, sem que isso implique na confirmação ou refutação da hipótese. Contudo, e isso configura uma limitação do presente estudo, ainda não dispomos de dados suficientes para testar a hipótese de forma categórica para o corpus em questão. 
Sem propor um foco de estudo prévio, apenas com o direcionamento de olhar para os eixos paradigmático e sintagmático de construção textual, buscamos deixar que as questões emergissem a partir dos dados. Assim, a observação de escolhas paradigmáticas e sintagmáticas nos levou aos seguintes questionamentos a serem futuramente investigados: a tradução teria uma tendência a usar unidades lexicais mais "difíceis", menos usuais, ou menos frequentes no português brasileiro? Haveria um padrão nessas escolhas? Teria a retradução optado por escolhas mais informais e mais próximas da fala cotidiana, ou mais usuais no português brasileiro? Seria uma estratégia editorial para popularização do romance em português brasileiro? Teria sido a retradução realizada para tornar o texto mais "acessível" aos leitores? O estudo aponta a necessidade de verificar se haveria um padrão na escolha de unidades lexicais mais frequentes no português europeu na tradução, bem como das escolhas referentes à colocação pronominal em ambas as traduções, além de questões relacionadas à dêixis e explicitação.

Mais do que encontrar respostas, nesse estágio inicial de pesquisa, objetivamos gerar perguntas em face de uma análise parcial dos dados. Essa exploração inicial apontou para caminhos de pesquisa a serem percorridos. Assim, ressaltamos a importância da realização de pequenos estudos-piloto ou exploratórios em investigações que façam uso de corpora informatizados.

\section{Agradecimentos}

Agradeço a dois pareceristas anônimos pelas sugestões. Qualquer inadequação que persistir é de minha inteira responsabilidade.

Agradeço a Coordenação de Aperfeiçoamento de Pessoal de Nível Superior - Brasil (CAPES) - Código de Financiamento 001 pelo apoio financeiro.

\section{REFERÊNCIAS}

BAKER, M. Corpus linguistics and translation studies: implications and applications. In: BAKER, M. et al. (ed.). Text and technology: In honour of John Sinclair. Amsterdam: John Benjamins, 1993. p. 233-250.

BAKER, M. Towards a methodology for investigating the style of a literary translator. Target, v. 12, n. 2, p. 241-266, 2000.

BERBER SARDINHA, T. Pesquisa em Linguística de Corpus com WordSmith Tools. Campinas: Mercado de Letras, 2009.

BERMAN, A. La retraduction comme espace de la traduction. Palimpsestes, n. 4, p. 1-7, 1990. 
BROWNLIE, S. Narrative Theory and Retranslation Theory. Across Languages and Cultures, V. 7, n. 2, p. $145-170,2006$.

BLAUTH, T. P. A paisagem indescritivel em Heart of Darkness e duas traduções brasileiras: um estudo exploratório de estilística tradutória com base em corpus. Belas Infiéis, v. 3, n. 1, p. 185-197, 2014.

CARNEIRO, R. M. O. The good, the bad, and the ugly sides of revenge in Hag-Seed. Interfaces Brasil/Canadá, v. 19, n. 2, p. 136-140, 2019.

CARNEIRO, R. M. O. The Heart Goes Last; or, taking the piss while being drop-dead earnest. Interfaces Brasil/Canadá, v. 18, n. 1, p. 143-151, 2018.

CARNEIRO, R. M. O. The High Mountains of Portugal, or gazing at Iberian rhinoceros roaming in the wild. Interfaces Brasil/Canadá, v. 17, n. 2, p. 149-154, 2017.

GAMBIER, Y. La retraduction, retour et détour. Meta, v. 39, n. 3, p. 413-417, 1994.

GIBBONS, A.; WHITELEY, S. Contemporary stylistics: language, cognition, interpretation. Edinburgh: Edinburgh University Press, 2018.

HALLIDAY, M. A. K. Language as system and language as instance: the corpus as a theoretical construct. In: SVARTVIK, J. (org.). Directions in corpus linguistics: proceedings of the Nobel Symposium. Berlin: Mouton de Gruyter, 1992. p. 61-77.

JAKOBSON, R. Linguística e comunicação. Tradução Izidoro Blikstein e José Paulo Paes. 19. ed. São Paulo: Cultrix, 2003.

JEFFRIES, L.; MCINTYRE, D. Stylistics. Cambridge: Cambridge University Press, 2010.

KOSKNEN, K.; PALOPOSKI, O. Retranslation. In: GAMBIER, Y.; VAN DOORSLAER, L. (org.). Handbook of Translation Studies. v. 1. Amsterdam: John Benjamins, 2010. p. 294-298.

KOSKINEN, K.; PALOPOSKI, O. Retranslations in the age of digital reproduction. Cadernos de Tradução, v. 1, n. 11, p. 19-38, 2003.

LAVIOSA, S. Corpus-Based Translation Studies: theory, findings, applications. Amsterdam/ New York: Rodopi, 2002. 
MAGALHÃES, C. M.; CASTRO, M. C de; MONTENEGRO, M. S. Estilística tradutória: um estudo de corpus paralelo de uma tradução brasileira e uma tradução portuguesa de Heart of Darkness. TradTerm, v. 21, p. 11-29, 2013.

MAGALHÃES, C. M.; BLAUTH, T. P. Estilo do tradutor: um estudo do uso do itálico, palavras estrangeiras e itens culturais específicos por seis tradutores do português de Heart of Darkness. In: VIANA, V.; TAGNIN, S. (org.). Corpora na tradução. São Paulo: Hub Editorial, 2015. p. 171-209.

MALMKJAER, K. Translational stylistics: Dulcken's translations of Hans Christian Andersen. Language and Literature, v. 13, n. 1, p. 13-24, 2004.

MASSADIER-KENNEY, F. Toward a rethinking of retranslation. Translation Review, v. 92, p. 73-85, 2015.

NOVODVORSKI, A. Estilo das traduções de Sergio Molina de obras de Ernesto Sabato: um estudo de corpora paralelos espanhol/português. 2013. Tese (Doutorado em Estudos Linguísticos) - Faculdade de Letras, Universidade Federal de Minas Gerais, Belo Horizonte, 2013.

PILLIÈRE, L. Structuralism and Stylistics. In: SOTIROVA, V. (org.). The Bloomsbury Companion to Stylistics. London: Bloomsbury Academic, 2018. p. 21-36.

SALDANHA, G. Translator style: methodological considerations. The Translator, v. 17, n. 1, p. 25-50, 2011.

SCOTT, M. WordSmith Tools version 6. Stroud: Lexical Analysis Software, 2012.

SINCLAIR, J. Corpus, concordance, collocation. Oxford: Oxford University Press, 1991.

TOURY, G. Descriptive translation studies - and beyond. Amsterdam: John Benjamins, 2012. 